\title{
The World Health Organization has Global Guidelines on Handling Cells, Tissue, Blood and Semen-- So Why is Breast Milk Left in the Dark?
}

\section{Jasmine Shafquat, JD}

Sharing breast milk is an ancient and well-established practice. In fact, Greek and Roman mythology, the Bible, the Torah, and Islamic scripture all describe women who shared their breast milk with children that were not their own kin. Despite the fact that this primeval practice is continuously used in modern times to save preterm lives, there are no global guidelines or regulations on breast milk sharing. By comparison, there are international standards for how cells, tissue, blood, and semen should be screened, selected, and shared. This gap in regulation is especially alarming given that donated breast milk is received by the world's most vulnerable population. Because there is a vast array of knowledge, experience, and research on safe and effective milk banking systems, it is time for the World Health Organization to implement a set of standards regarding the treatment and distribution of banked breast milk. Global direction on human milk banking would help frame some of the concerns, expedite their resolution, and remove the stigma associated with this practice. This Note will give a pragmatic set of recommendations for the World Health Organization to adopt. This Note will begin by discussing the worldwide proliferation of breast milk banks. It will then analyze differing breast milk networks in Brazil, Norway, and the United States to generate an understanding of current milk banking practices and determine what is working and what is missing from these regulatory regimes. Ultimately, this Note aims to provide policymakers with a framework for implementing safe standards and international cooperation with breast milk banking.

\section{Introduction}

Breast milk has always been highly regarded as a vital source of nutrition and has even earned the nickname "liquid gold". (1) Over the last several decades there has been an increased interest in selling and sharing breast milk across the globe.(2-5) This is, at least in part, due to substantial changes in the process of breast milk sharing. The practice of milk sharing originated with wet nursing, which was considered a "practical way to provide nutrition for infants and reinforce social class distinctions." (6) The practice of breast milk sharing has since changed due to changes in clinic knowledge, technological advancements, and social norms and further discussion of these changes will be in part II. Particularly, the informal circulation of breast milk has now become more accessible with Facebook, Craigslist, and a plethora of other websites providing a platform for these exchanges to occur. $(7,8)$ Moreover, the formal distribution of breast milk, through institutionalized human milk banking systems, has multiplied considerably over the past few decades. There are now an estimated 500 human milk banks operating in more than thirty-seven countries (3) This Note will primarily focus on the more formal method of breast milk distribution because the nutrition community has generally discouraged informal breast milk sharing $(6,9,10)$ and encouraged institutionalized breast milk banking. (2)

\section{Readers can also follow}

via our Twitter Feed
The World Health Organization (hereinafter "WHO" or "Organization"), American Academy for Pediatrics, the Committee on Nutrition of the European Society for Pediatric Gastroenterology, Hepatology, and Nutrition, and various other policy groups recommend donated breast milk, from human milk banks, as the optimal feeding alternative to maternal breast milk. (11) Most of these organizations provide guidelines for using donated breast milk to prevent false information from spreading and to ensure that the practice is executed safely.(12) Yet, there are no further standards given by WHO to implement the practice of donating and using breastmilk. What is more, WHO has endorsed a set of principles for how cells, tissues, organs, blood, and semen should be selected and screened. WHO could propose a set of principles for breast milk, as it does for these other similar "medical products of human origin." (13) The question then arises, why has WHO failed to endorse standards regarding breast milk handling when it has historically endorsed other similar standards, (14) especially in light of the fact that it advocates for the use of donor human milk? (15)

\section{"The question then arises, why has WHO failed to endorse standards regarding breast milk handling when it has historically endorsed other similar standards, (14) especially in light of the fact that it advocates for the use of donor human milk?"}

This Note proposes that $\mathrm{WHO}$ can and should provide "best practices" regarding the selection and examination of breast milk. This Note will justify the recommended response by first examining the factors contributing to the booming market in banked donor milk. It will then address the current state of the regulatory gap and discuss the substantial and important role WHO plays in addressing this concern. Finally, the Note examines milk banking practices in Brazil, Norway, and the United States to identify best practices for WHO to endorse. Based on these countries' experiences, as well as what is accepted by the scientific community, the Note then proposes that WHO should adopt specific guidelines for selecting breast milk donors and collecting, processing, handling, testing, and storing breast milk. By adopting the proposed standard, WHO can clarify confusion regarding its own recommendations, increase the chances of infant health and infant survival, and ultimately become one step closer to achieving its global health target in promoting the health and safety of infants and young children. (16)

\section{Background: What is Driving the Booming Market in Breast Milk Banking?}

Social attitudes regarding donor milk and milk sharing have fluctuated over time. In 1914, "donor banked milk" entered the medical literature when a physician noted that sick children "do very much better if they are fed wholly or in part on human milk." (8) Thereafter, donor milk banks slowly started emerging in hospitals. By the 
1980s, the number of milk banks began to increase dramatically. However, in the early 1990s, donor milk banks began to decline due to a growing fear of HIV transmission and the increased availability of "specialty infant formulas." The current trend reveals that breast milk banking is becoming much more accepted and appreciated on an international scale. (17) A 2016 study on Kenyan public attitudes demonstrated that even when people were unfamiliar with the concept of human milk banks, most people supported human milk banks once they became educated on how breast milk banks operated. (18) Further, the growing demand for human milk and the subsequent increase in breast milk banking is unlikely to dwindle due to a combination of the following factors: the increased body of knowledge establishing breast milk as the optimum source of nutrition; some of the barriers to breastfeeding compelling mothers to select alternative infant feeding options; the investment in breast milk banks due to the global influx in preterm birth rates; and various socio-cultural changes. It should be noted that this Note only discusses some of the leading factors contributing to the demand in breast milk, it is in no way an exhaustive list of reasons for this increase.

\section{World-Wide Recognition that "Breast is Best"}

International acknowledgment and support that breast milk is the optimal feeding option is pushing the proliferation of institutionalized breast milk banks. (2) First, global advocacy for breast milk is exemplified by WHO's own directive, which provides that in health situations where an infant cannot or should not use her mother's milk, donated breast milk is the best alternative and infant formula is regarded as the less desirable alternative. (15) This is largely because breast milk is species specific. Even the most advanced, high-quality infant formulas cannot replicate the "bioactive matrix of benefits" that breast milk provides.(19) This is not to say that babies cannot grow up happy and healthy on infant formulas. (20) However, scientific and medical research has established that breast milk is essential for proper growth, nutrition, and the prevention of complications that could result in longer-term care, expenses, or premature death. Nonetheless, it is crucial that vulnerable infants-such as those who are born preterm or with low birth weight, are orphaned, or are severely malnourished-have access to human breast milk for proper growth, nutrition, and the prevention of infections or other complications that may lead to longer-term care, expenses, or premature death. $(3,21)$ Specifically, evidence-based research demonstrates that formula feeding is linked with an increased risk of necrotizing enterocolitis (NEC) (22), sudden infant death syndrome (SIDS) (23), ), and childhood obesity. (24) It is undeniable that breast milk is the most inexpensive, sustainable, and accessible method to provide all children, rich or poor, with the healthiest start to life. (11) There are some individuals that believe the benefits of breast milk are overemphasized, arguing that many studies on the benefits of breastfeeding are biased because women who breastfeed differ than those who do not-based on income, education, and race. They also argue that very few breastfeeding studies adjust for these differences across women and those studies that do adjust for the aforementioned factors, are are not reliable because there are other unaccounted for characteristics that could be influencing the data, such as maternal IQ. (1) However, it is almost universally accepted that breast milk is the ideal source of nutrients for infants.(19)

\section{Barriers to Breastfeeding}

A woman's decision to breastfeed is extremely complex. (25) Understanding some of the factors that influence a mother's decision to breastfeed can help explain why banked breast milk has become progressively popular. For some women, breastfeeding is simply not a viable choice. Women with "insufficient glandular tissue (hypoplastic breasts), polycystic ovary syndrome (PCOS), hypothyroidism, a previous breast surgery, or prior radiation treat- ment for breast cancer" may not have the ability to produce a sufficient breast milk supply. (26) Additionally, some mothers may smoke cigarettes, drink alcohol, take medication, or have diseases that can be passed to their baby through breast milk. In those instances, the risk of transmitting certain substances or diseases greatly outweighs the benefits of breastfeeding. Still, it is important to note that alcohol and cigarettes can both be used while breastfeeding, in moderation. For instance, mothers may choose to express milk and bottle feed to prevent exposure to smoke or to time feeds depending on when substances will be present in the milk. (27) Research has also identified that "having an unsupportive partner, feeling embarrassed, [and] concerns about pain" are some other reasons why a woman may not initiate breastfeeding. (28). Even though breastfeeding is widely considered superior to other forms of infant feeding, many mothers are nonetheless pressed to choose a different feeding option because breastfeeding is unsafe, impossible, or undesirable. (19)

\section{"Feeding babies exclusively with human milk in the first hours, days, and months of life has the greatest potential impact on child survival and development. It is therefore imperative that preterm infants and also those who have low birth weights, are orphaned, or are severely malnourished, have access to human breast milk in order to prevent unnecessary neonatal deaths."}

\section{Global Influx in Preterm Birth Rates}

Another factor contributing to the growth of human milk banks is the global influx in preterm birth rates. Each year there are approximately 15 million babies born prematurely (one in ten of all babies born around the world). Almost all countries, rich and poor, are experiencing an increase in premature births. The proliferation in premature birth rates is especially problematic because prematurity is the world's leading cause of neonatal deaths. (29) Notably, a majority of these neonatal deaths are preventable and of all existing approaches, "feeding babies exclusively with human milk in the first hours, days, and months of life has the greatest potential impact on child survival and development. It is therefore imperative that preterm infants and also those who have low birth weights, are orphaned, or are severely malnourished, have access to human breast milk in order to prevent unnecessary neonatal deaths. Consequently, investments in human milk banks are emerging all over the world as an effective mechanism to save preterm lives and advance the chances of survival of all vulnerable infants. (30)

\section{Cultural-Shifts}

The increased demand for sharing and selling breast milk can also be attributed to several socio-cultural changes across the globe. One of the most significant changes of the last century has been the substantial increase in women participating in the labor force. (31) Although working is not dispositive of a woman's ability to breastfeed, "returning to work" is the most common reason that women stop breastfeeding and start supplementary feeding options. It should be noted that there are local and national laws, as well as corporate policies, put into place to support breastfeed- 
ing breaks and facilities in the workplace. (32) However, women at higher paying jobs are the ones that disproportionately experience the benefits of these initiatives. For instance, new mothers who work at Starbucks' corporate headquarters are able to pump breastmilk in lactation rooms with plush recliners whereas new mothers who staff the chains counters are restricted to pumping their milk in small restrooms intended for customers. (33) The harsh reality is that a vast number of companies still do not accommodate their employees with clean facilities for pumping and storing milk. Of the companies that do provide the necessary facilities, many employees are still subjected to timed breaks that make compliance very difficult or virtually impossible. (32) Subsequently, obtaining donor human milk is just one way for some working mothers to circumvent the obstacles of pumping at work. (34) Another socio-cultural change contributing to the demand in human milk likely stems from the increased number of couples adopting and using reproductive technology. Correspondingly, male same-sex parents, in particular, who want to raise their children on human milk have turned to breast milk banks to feed their infant children. This also extends to non-binary or non-gender identifying couples, or single fathers. (35) Lastly, there are several "wholesome" or "natural" food movements contributing to a preference for "natural" breast milk over "artificial" infant formulas. (17) For those parents with the resources to choose, many are opting for donated human milk rather than formulas derived from plants grown with pesticides and fertilizers. (36)

\section{Dangers of the Regulatory Gap}

Many parts of the world have no substantive regulation over breast milk sharing at all. (13) The absence of standards regarding breast milk sharing can result in health risks that endanger the lives of susceptible infants. (8) Some of these health risks include the transmission of certain infectious agents, like bacteria or viruses, from women who are not experiencing or showing symptoms themselves. (9) Particularly, CMV, HTLV-I, HIV 1 and 2 , human T-cell leukemia virus 1 and 2 , hepatitis $B$, hepatitis $C$, and syphilis are just some of the agents that can be transmitted through breast milk. (37) In addition, medicine and drugs can also be unintentionally transferred from contributor to recipient infant if proper screening and testing procedures are not in place. Furthermore, unhygienic storage and handling of breast milk can result in environmental contaminants that cause infection or disease. (9) The regulatory gap on breast milk sharing can also have an adverse impact on the emotional well-being of the parents who sought to give their infant optimal nutrition, but instead served their child contaminated breast milk. Some parents may be so embarrassed or ashamed that their child became sick from contaminated breastmilk that they are unwilling to disclose or report what happened, which further exacerbates the issue. (8)

\section{"Many parts of the world have no substantive regulation over breast milk sharing at all. (13) The absence of standards regarding breast milk sharing can result in health risks that endanger the lives of susceptible infants."}

An additional risk of the regulatory gap is that it creates a "gray market" where sharing and selling breast milk is unregulated, but not illegal. $(38,39)$ This "gray market" in breast milk subsequently spreads misinformation and allows individuals to sell counterfeit or diluted breast milk without consequence. (38) Furthermore, when breast milk is obtained off the internet, it can be more difficult to prove that an infant's sickness or condition was caused by the contaminated breastmilk. (1) This Note proposes that increased regulation would help prevent these situations by taking counterfeits off the market and providing legal protection to those families that want to acquire donated breast milk.

It is important to understand that many of the risks associated with unregulated breast milk are the same risks associated with unregulated formula or solid baby foods. (40) Therefore, it is not that breast milk itself is an inherently more dangerous product, but that sharing breast milk without substantive regulation is an inherently more dangerous practice. (1) Hence, many of the risks of sharing and selling breast milk can be prevented with guidelines, resources, and increased public awareness on the correct use and handling of breast milk. Brazil and Norway are examples of two countries that have demonstrated that the practice of sharing and selling breastmilk can be executed safely, as discussed in part IV.

\section{"Brazil's milk banking network "is credited with saving [the country] an estimated US \$540 million annually in medical costs." (42) " "It has also contributed to the country's remarkable progress in reducing infant mortality. $(43)^{g \prime}$}

\section{Milk Banking Practices Across the Globe}

In order to address the health concerns associated with the regulatory gap on breast milk, while also recognizing that access to breast milk reduces infant mortality and illness, as well as lowers health care costs (11), thirty-seven countries have implemented robust laws surrounding breast milk banking. Many of these countries have modeled their regulatory regimes based on Brazil's milk banking system. (41) Nonetheless, the implementation and operation of breast milk banking systems can vary from country to country. This is because factors such as a nation's culture, resources, and disease risk pool all play an integral role in determining how breast milk banks are structured. There are, nevertheless, fundamental similarities between effective milk banking systems. (5) As a result, this Section examines milk banking practices in Brazil, Norway, and the United States to understand the differing approaches and to identify a framework of best practices.

\section{Brazil: The Global Leader in Breast Milk Banking}

Brazil is considered the "global leader" in human milk banking. (5) Brazil's title is well-deserved not only because it has the largest milk banking network, but also because the country's efforts have proven to be incredibly effective. $(42,43)$ Brazil's milk banking network "is credited with saving [the country] an estimated US $\$ 540$ million annually in medical costs." (42) ." It has also contributed to the country's remarkable progress in reducing infant mortality. (43) . Notably, Brazil's milk banking system and public health policies have been replicated by resource-poor and resource-rich countries alike "given the success and the nature of the Brazilian model." (44) The Brazilian model, therefore, is a useful starting point for determining how breast milk should be regulated on a global scale.

\section{Brazil's Milk Banking Network}


Breast milk banking in Brazil can be traced back to the 1930s. (5) In the last thirty years, however, breast milk banks have become integrated into Brazil's public health system. $(44,45)$ Today, Brazil has approximately 217 human milk banks and there is at least one bank in each of the country's twenty-six states. Furthermore, Brazil's milk banking system is not only vast, but centrally organized. The Oswaldo Cruz Foundation (hereinafter "FIOCRUZ" or "FIOCRUZ Institute") serves as a national reference bank for the entire country. (46) It is important to note that FIOCRUZ is a scientific institution for research and development, which operates under Brazil's Ministry of Health. (47) FIOCRUZ promotes and protects safe and effective milk banking practices in a number of different capacities. (45) For instance, in addition to serving as a national reference bank, FIOCRUZ also does the following:

1) Oversees national networking among HMBs [human milk banks], communicating information in the field of milk banking, monitoring the compliance of donor milk banks with the national milk banking guidelines regarding quality control of donor milk supplies, organizing periodic conferences to improve milk banking services, and training professionals to work in HMBs;

2) acts as the liaison with the government to comply with the policies of the Ministry of Health;

3) conducts research in the areas of the basic and social sciences as well as the development of quality control methodology to lower processing costs and still maintain a quality product to meet national needs;

4) disseminates information among HMBs; and

5) publishes a biannual bulletin (Gota de Leite) which is distributed to all HMBs(45)

FIOCRUZ's oversight of the country's milk banking network, research on safe and effective milk banking methods, and continuous collaboration with government officials has played a substantial role in Brazil's accomplishments with breast milk banking. (45)

\section{The Brazilian Regulatory System}

Brazil has adopted clear and comprehensive guidelines that detail all of the steps necessary to establish and operate a human milk bank. (45) These regulations were initiated in the mid-1980s and have been periodically updated as the scientific and medical community has become better informed about human milk and its properties. Many of these regulations stem for evidenced-based recommendations from the FIOCRUZ Institute. (47) Remarkably, Brazil's requirements for screening, storing, and handling breast milk are simple and can be implemented at a relatively low cost. (48)

The standards set forth by the Agência Nacional de Vigilância Sanitária (The Brazilian Health Regulatory Agency, hereinafter "ANVISA"), require breast milk donors to be "healthy" already lactating individuals who produce more milk than their own children need. (49) The regulation further states that donors cannot drink, smoke, or use any drugs incompatible with breastfeeding and must be willing to comply with preliminary screening tests. (50) Another related requirement is that donors cannot receive payment for their breast milk. . Specifically, the ANVISA stipulates that the donation of breast milk "must be voluntary, altruistic and unpaid, directly or indirectly". (51) Notably, this condition is not unique to breast milk. In Brazil, the donation of all biological material, such as organs, blood, cells, and genes must be "free and subject to voluntary consent." In fact, Brazil's Constitution "adopts the principle of 'no commodification' of the human body." Moreover, this principle has been continuously upheld through various other legal instruments. (52) Because altruism has been a longstanding principle embedded in Brazil's legal and social system, the requirement for free and voluntary donations has not noticeably hindered the country's ability to recruit donors. In fact, in 2016 , there were approximately 171,967 breast milk donors who collectively gave 183,035 liters of breast milk, and 166,000 infants benefited from these donations. (46) . While the requirement to keep donors uncompensated may be problematic for some, encouraging donors to charitably give their surplus breast milk evidently works in Brazil. $(53,54)$

\section{"An additional handling requirement stipulates that all donated breast milk has to be pasteurized. Pasteurization is beneficial for breast milk because it inactivates viruses present and reduces microbial contamination. However, pasteurization also destroys breast milk fat concentration and energy content that help infant resistance against a number of diseases."}

In regard to storage and handling, ANVISA requires specific temperature ranges for the transportation, storage, and distribution of breast milk. (55) The regulation further stipulates that institutionalized milk banks must provide adequate, sterilized containers for each donor.(56) It should be noted that storage and handling practices have changed considerably after several years of trial and error. Initially, breast milk banks used "imported beaker tubes that had accounted for a whopping eighty nine percent of operating costs at Brazilian milk banks," Now, breast milk banks use sterilized "jars made for mayonnaise or instant coffee" to store milk for freezing. (48) These vessels are significantly cheaper while still meeting the requisite requirements that the container must:

1) be of material that can be easily cleaned and disinfected;

2) present a closure in order to maintain the integrity of the product;

3) be constituted of inert and harmless material to the LHE with temperatures from $-25^{\circ} \mathrm{C}$ (twenty-five degrees Celsius negative) to $128^{\circ} \mathrm{C}$ (one hundred and twenty-eight degrees Celsius) that preserves its biological value.(57)

An additional handling requirement stipulates that all donated breast milk has to be pasteurized. (45) This is arguably one of the country's most salient regulations since there are several advantages and disadvantages to pasteurizing breast milk. Pasteurization is beneficial for breast milk because it inactivates viruses present and reduces microbial contamination. However, pasteurization also destroys breast milk fat concentration and energy content that help infant resistance against a number of diseases. (58) Nonetheless, "new pasteurization methods aimed at maintaining the safety of pooled human milk while better preserving bioactivity are under investigation." As such, pasteurized breast milk is still preferred over infant formula. (59) Nevertheless, similar to the container requirements, execution of Brazil's pasteurization 
requirements have been altered to become more feasible and cost-effective. Specifically, "high-end pasteurizing machines that cost $\$ 25,000$ were swapped for $\$ 1,500$ Brazilian-made machines used in food-testing laboratories."(60) Scientists and public health officials in Brazil have been able to collaborate together to "adapt the system . . . without compromising the quality and safety of the milk." (48) Brazil's collaborative efforts demonstrate that a robust banking network can be implemented efficiently and can function off low-cost technology when clear and comprehensive regulations are in place. For this reason, the Brazilian model is considered "the ideal model" for low-income nations." (44)

\section{Brazil's Awareness and Advocacy Programs}

Brazil's accomplishments can be traced to numerous public health initiatives concerning the promotion, protection, and support of both breastfeeding and breast milk banking. In regard to the former, the Brazilian government has taken significant steps towards integrating breastfeeding into the country's universal primary health care system. (5) The country's first stride toward integration began in 1981, when Brazilian health authorities launched the Programa Nacional de Incentivo ao Aleitamento Materno (Brazilian National Breastfeeding Program, hereinafter "PNIAM") due to the alarming rate of early cessation of breastfeeding at the end of the 1970s. PNIAM started as a mass media campaign to inform the public of the "various aspects of breastfeeding and the importance of breast milk." With assistance and cooperation from different community, administrative, education, and health authorities, the program was able to rapidly expand. PNIAM subsequently implemented the following measures to further its objective of increasing the use and duration of breastfeeding in Brazil: (61)

1) Train and update health professionals regarding breastfeeding;

2) Encourage research benefiting the [PNIAM];

3) Orient and sensitize non-professional health workers;

4) Convince administrators to redirect maternity structures to facilitate natural breastfeeding (in particular, by arranging for rooming-in facilities);

5) Include "breastfeeding" in health studies curricula; and in the study curricula of primary school teacher training and literacy teacher training;

6) Create a Brazilian Code, based on WHO/UNICEF International Code of Marketing of Breast milk Substitutes;

7) Implement labor laws for protecting the working mother;

8) Form mothers' self-help groups;

9) Disseminate information on breastfeeding among authorities, making them aware of its long-term benefits; and

10) Inform mothers about breastfeeding both through personal contact and through the media. (61)

Two especially significant efforts include the passage of legislation that restricts the way in which formula companies can market their products, as well as legislation that guarantees four months of maternity leave for new mothers. (62) Importantly, these regulations and many of the other measures implemented by PINAM can be attributed to directives from World Health Organization (WHO) and the United Nations Children's Fund (UNICEF), such as Baby-friendly Hospital Initiative (1991), the International Code of Marketing of Breast-milk Substitutes (1981) and the Innocenti Declaration on the Protection, Promotion and Support of Breastfeeding (1990). (61)
The success of PNIAM is demonstrated by a number of studies conducted over the last decade. $(63,64)$ One cross sectional study in 2011 demonstrated that the prevalence of exclusive breastfeeding for infants older than six months in Ribeirao Preto, Brazil, was significantly higher in places accredited by the Brazilian National Breastfeeding Program.(43) Additionally, according to the National Survey on Maternal and Child Health and Family Planning, the prevalence of exclusive breastfeeding among children under six months increased from 2.9 percent in 1986 to 36.6 percent in 2013 . This is a total increase of 34.2 percentage points through 2006. Id. There were "statistically significant gains in each decade until 2006 and stabilization in 2013." The survey further demonstrated that prevalence of breastfeeding during the first year of life increased from 22.7 percent in 1986 to 45.4 percent in 2013. This is "a total increase of 22.7 percentage points in the period, stabilizing between 2006 and 2013." (62) It is evident that the Brazilian government's efforts have contributed to a considerable improvement in the country's breastfeeding rates. (62-64) Today, breastfeeding is even considered a cultural norm in Brazil.(46) Importantly, normalizing breastfeeding in Brazil has the added benefit of normalizing donor milk banking throughout the country as well. (45)

\section{"It is evident that the Brazilian government's efforts have contributed to a considerable improvement in the country's breastfeeding rates. (62-64) Today, breastfeeding is even considered a cultural norm in Brazil..(46) Importantly, normalizing breastfeeding in Brazil has the added benefit of normalizing donor milk banking throughout the country as} well."

In conjunction with the Brazilian government's efforts to encourage breastfeeding, the government has also taken steps to specifically support donor milk banking in Brazil. (45) First, the Brazilian government has developed creative ways to highlight the importance of breastfeeding through its own employees. For instance, "Breastfeeding Friendly Postman Program" instructs letter carriers to share pamphlets and resources to pregnant women as they go door-to-door delivering mail and "Project Firefighter - Breast Friend" instructs firefighters on how to properly pick up breast milk for donation from a mother's home. (65) Another initiative is the "Feed and Breastfeed Brazil Strategy," which integrates breastfeeding and complementary feeding within the country's primary health care system. These are just some of many governmentsponsored initiatives that have been implemented over the last several years. (64)

Notably, the Brazilian government has also promoted donor milk banking on both a national and international scale. To foster milk banking on a national scale, the Brazilian Ministry of Health created the Bancos de Leite Humano (Network of Human Milk Banks, hereinafter "BLH-BR"), to encourage breast milk banking across Brazil. One of the BLH-BR's most impressive initiatives was the creation of the "National Day of Human Milk Donation." On this day, an actress, singer, athlete, or other public figure would inform the public about the importance of donating breast milk. (66) Because of the success of the "National Day of Human Milk Donation," Brazilian officials became interested in organizing a world- 
wide day to celebrate milk banking. (67) Accordingly, Brazil began collaborating with other countries and ultimately launched the Iberoamerican Program of Human Milk Banks (hereinafter "IberBLH"). ") This coordination resulted in the creation and adoption of the "First Letter of Brasilia" on May 19, 2010.(66) The "First Letter of Brasilia" is credited with "[laying] the groundwork for international cooperation in milk banking." (68) For this reason, May 19 is the designated date for "World Human Milk Donation Day."(66) Today, the idea of a global day to raise awareness about breast milk donation has "spread from its largely South and Central American roots, to become a truly global event." (69) Across the globe, countries are celebrating "World Human Milk Donation Day" to honor and celebrate those who donate breast milk to nonprofit milk banks. Posters, brochures, inserts in TV stations and broadcasting are instruments used to disseminate the importance of donating human milk, in a campaign always focused on the slogan "For you it is milk, for the child it is life. Donate milk, life is grateful." (70) Brazil's exemplary awareness and advocacy initiatives have undoubtedly contributed to the country's accomplishments with donor milk banking.(66) What is more, it is clear that the Brazilian government's commitment to promote and protect breast milk banking has had a positive impact not only on Brazil, but also the world. (54)

All in all, the Brazilian model can be summarized as "simple, efficient, and economically feasible." (44) Brazil has made safe and effective breast milk banking a top priority by investing in an allencompassing, yet centrally-organized infrastructure; creating clear and comprehensive legislation; and implementing outstanding education, awareness, and advocacy programs throughout the country. $(5,44,45)$ These efforts have proven to be worthwhile given that the country's milk bank system is cited as a key component to the country's drastic decline in infant mortality.(71) Although no other country has come close to reaching Brazil's success yet,(5) it comes as no surprise that rich and poor countries alike have started to replicate the Brazilian model.(71)

\section{Norway: A Contrasting Approach to Breast Milk Banking}

Norway is another country that has developed a safe and successful milk banking system. (5) Norway has an "almost universal" initiation of breastfeeding with only one percent of babies never receiving any breast milk. (72) Further, any infant that needs donated breastmilk is provided it free of charge. Norway stands out in the world of milk banking because it has implemented regulations that differ drastically from those of Brazil.(5) More specifically, Norway has distinctively tailored its breast milk banking system to fit the country's culture and population base, which is notably forty times smaller than Brazil's population. $(73,74)$ There are, nevertheless, some overlapping mechanisms shared between Norway's unique milk banking system and other successful milk banking systems. Together, the Brazilian and Norwegian models ultimately demonstrate that with strong governmental support and regulation over breast milk banking a country can increase its breastfeeding rates and create an effective milk banking network that saves lives. (5)

\section{Norway's Milk Banking Network}

Norway's first breast milk bank was established in 1941. Thereafter, the number of milk banks sharply increased and eventually peaked in the late 1990s with seventeen milk banks throughout the country in 1997. (75) Norway currently has twelve active milk banks that generate a sufficient supply of breast milk for the country's needs.(76) Each milk bank is affiliated with a hospital and connected to the hospital's neonatal intensive care unit. The affiliated hospital is then responsible for overseeing the operation of the breast milk bank. Interestingly enough, Norway's breast milk banks are united informally and there is not a single, specific bank that serves as a reference for the entire country. Instead, Norwegian milk banks use a Facebook page titled "Milk Banks in Norway" as a platform to stay informed and connected with one another. There is also a closed Facebook group titled "The milk banks in Norway" that serves a platform for milk bank employees to discuss and share internal experiences. Although the Norwegian milk banks generally collaborate in an unofficial manner, every milk bank nonetheless reports to a designated person each year. The designated person then generates an annual report for all of the milk banks, which depicts the number of donors and the number of liters of milk generated at each facility. (77)

"Norway has an "almost universal" initiation of breastfeeding with only one percent of babies never receiving any breast milk. (72) Further, any infant that needs donated breastmilk is provided it free of charge."

\section{The Norwegian Regulatory Network}

Like Brazil, the Norwegian National Board of Health (hereinafter "NNBH") has implemented a robust set of guidelines that have contributed to the country's success with breast milk banking. The guidelines define "the organizational structure of the milk banks, what equipment is to be used and how it must be maintained, donor qualifications and exclusion criteria, and procedures for screening, handling, and dispensing the milk." However, distinct from Brazil, Norway's regulations are based on a long tradition of using raw, unpasteurized breast milk. Only one of thirteen breast milk banks in Norway pasteurizes all donor milk. The use of raw milk is actually a plausible option in Norway because the country has a very low incidence of HIV and hepatitis, as well as a high standard of living and high breastfeeding rates. (75) Correspondingly, systemic pasteurization is not required in Norway. Norwegian milk banks have instead implemented an "extremely rigorous and regularly repeated" testing process to bypass the pasteurization process. (46) Under this system, breast milk donors are initially tested for various diseases and risk factors and subsequently undergo a blood test every three months. (75) Each container of donated breast milk is further screened for pathogens and bacteria. Any breast milk that contains unwanted pathogens or a high count of bacteria is discarded altogether. (77)

NEONATOLOGY TODAY is interested in publishing manuscripts from Neonatologists, Fellows, NNPs and those involved in caring for neonates on case studies, research results, hospital news, meeting announcements, and other pertinent topics. Please submit your manuscript to: LomaLindaPublishingCompany@gmail.com 
NNBH essentially regulates breast milk banks like blood banks. Comparable to the laws governing blood banks, all breast milk banks in Norway must have a system for tracing the milk from the donor to the recipient and from each recipient back to the donor. (75) The NNBH's regulation of milk banks, like blood banks, is a an appropriate measure to ensure the milk's safety given the disposition of Norway's population. Thus, it is important to note that the Norwegian model for breast milk banking may not be appropriate to replicate in countries with higher rates of communicable diseases. (5)

Norway's donor compensation process is another notable difference between Norwegian law and Brazilian law, which is considered the norm. In most countries that regulate breast milk banking, breast milk is gifted and donors cannot be paid directly or indirectly. $(5,49)$ In Norway, a direct payment for breast milk is generally prohibited. However, Norwegian national guidelines allow a donor to be reimbursed for certain expenses incurred such as electricity, parking, and toll roads. Compensation for donors varies and some Norwegian milk banks do not reimburse donors at all. (75) Nonetheless, it is not unusual for milk banks to provide donors with a small reimbursement of about 150 NOK per liter (about \$20 US per liter) of breast milk. $(75,77)$ Norway's regulatory system thus attempts to minimize the financial burden imposed on mothers for donating their milk. (5)

\section{Norway's Awareness and Advocacy Programs}

Analogous to Brazil, Norway's success with milk banking can also be attributed to several initiatives protecting, promoting, and supporting both breastfeeding and breast milk banking. First, like many other industrialized nations, Norway experienced a significant reduction in breastfeeding rates at the end of the twentieth century. To address this concern, Norwegian health authorities entered into a voluntary agreement with officials in the food industry to regulate the way in which infant formula was advertised. Importantly, this agreement was entered into in 1983, which was shortly after the WHO Code of Marketing of Breast Milk Substitutes (1981) was enacted. The Norwegian health authorities suitably adopted many but not all of the WHO's recommendations. On the other hand in 2001, to further improve the country's breastfeeding rates, the Norwegian Government amended the country's infant feeding recommendations to mirror WHO's guidelines. The Norwegian Health Department has since issued several publications on infant feeding in accordance with both the government and WHO's endorsements for exclusive breastfeeding.(78)

The enactment of legislation that generously extended parental leave is another way in which the Norwegian Government promoted breastfeeding and breast milk banking. Under Norwegian law, parents are entitled to forty-six weeks at full salary, or fifty-six weeks at eighty percent pay.(78) The law further stipulates that mothers who do not qualify for parental leave are still entitled to a lump-sum payment. (77) Altogether, these regulations have the mutual benefit of safeguarding both breastfeeding and breast milk banking by reducing some of the economic burdens imposed on mothers. $(77,79)$

The Norwegian Government has implemented a number of measures to promote, protect, and support breast milk banking on an international level as well.(79) As a member of the European Milk Banking Association (hereinafter "EMBA"), Norway advocates for breast milk banking across Europe and encourages international cooperation between milk banks. Moreover, every two years participating countries in the EMBA join forces at an international conference to improve breast milk banking. (77) In addition to participating in the EMBA, the Norwegian Government has also assisted in the development of breast milk banks and lactation counselling centers in India. The Norwegian Government has demonstrated a commitment to promoting safe and effective milk banking systems not just within Norway, but across the globe. (80)

It is evident that the Norwegian Government's initiatives have improved the country's breastfeeding rates and infant health outcomes. The prevalence of breastfeeding mothers substantially increased from less than 5 percent in 1968, to more than 90 percent today.(81) Further, the country's infant mortality rate has decreased from 13.526 percent in 1968 , to I.921 percent today. (82) Given Norway's remarkable accomplishments, it comes as no surprise that the country is praised for promoting, protecting, and supporting both breastfeeding and breast milk banking. (81)

\section{"Distinct from Brazil and Norway, in the United States there are not any federal regulations or federal public health policies concerning breast milk banking. (83) It is not clear why the U.S. Food and Drug Administration has deliberately declined to regulate breast milk banks, especially when the administration oversees blood, cord, oocytes, semen, and stool banks."}

\section{The United States: A Hands-off Approach to Breast Milk Banking}

Distinct from Brazil and Norway, in the United States there are not any federal regulations or federal public health policies concerning breast milk banking.(83) It is not clear why the U.S. Food and Drug Administration (hereinafter "FDA" or "the administration") has deliberately declined to regulate breast milk banks, especially when the administration "oversees blood, cord, oocytes, semen, and stool banks."(53) Nonetheless, the FDA has acknowledged the benefits of using donor human and has advised against feeding infants with breast milk obtained directly through individuals or from the internet. This overall lack of guidance from the federal government has not been substituted for state-based regulations either. Only a few states require breast milk banks to adhere to certain safety standards.(84) Accordingly, institutionalized breast milk banks have largely become self-regulating entities that voluntarily adhere to scientific standards and procedures for the delivery and production of breast milk.(53) However, the country's hands-off approach proliferates the number of individuals that buy and sell breastmilk informally, and these individuals may not be

New subscribers are always welcome! NEONATOLOGY
To sign up for a free monthly subscription, just click on this box to go directly to our subscription page 
following recommended best practices. $(1,53)$ This system additionally raises concerns regarding the accessibility, cost, and acceptance of breast milk banking.(53) The U.S. model ultimately exemplifies the imperative need for global direction on human milk banking. (1)

\section{The Haphazard Milk Banking Network and System in the U.S.}

There are twenty-six nonprofit milk banks, and five nonprofit milk banks that are in the development process in the United States. All of these nonprofit breast milk banks have been accredited by the Human Milk Banking Association of North America (hereinafter "HMBANA"). (85) HMBANA is a professional organization that oversees nonprofit milk banking in the U.S. and Canada.(86) Specifically, the organization aims to advance the field of nonprofit milk banking by accrediting certain banks, developing evidence-based best practices, and advocating for breastfeeding and breast milk banking. (83) In an effort to achieve this goal, HMBANA establishes voluntary guidelines for member banks for screening potential donors, and for collecting, processing, handling, testing and storing milk. Hence, all of the non-profit milk banks that have been accredited by HMBANA have met the minimum standards set forth in HMBANA's Guidelines for the Establishment and Operation of Donor Human Milk Banks (2011).

On the other hand, there are three for-profit milk banks in the United States that provide safe breast milk even though these companies are not accredited by HMBANA.(87) Some of these for-profit milk banks even claim that they provide a better form of quality assurance than HMBANA banks. Nevertheless, the primary difference between for-profit and nonprofit milk banks is not necessarily a distinction between the quality of breast milk at each facility. (53) Rather, the difference between these two organizations boils down to conflicting policy preferences. For-profit companies generally assert that breast milk donors deserve to be compensated due to the "tolling" milk donation process. (87) Correspondingly, for-profit milk banks tend to regulate milk banks similar to egg and sperm banks.(1) Nonprofit companies take the opposing view and stress that breast milk donations should be completely altruistic. (87) Accordingly, nonprofit milk banks tend to regulate breast milk similar to blood banks. It is not evident that one approach is necessarily superior to the other. Both for-profit and nonprofit milk banks in the U.S. have provided families with safe breast milk without exploiting donors, but this is predominantly because these entities have voluntarily self-regulated themselves. The primary issue with the country's approach, therefore, lies with those individuals who exchange breastmilk without conforming their behavior to nationally-recognized standards. (53)

"Stories about parents purchasing contaminated breast milk online have unfortunately become an increasingly popular headline in U.S. news. $(88,89)$ These articles can indirectly mislead the public about other, safer forms of breast milk sharing. "

\section{The Need for Government Regulation and Support of Donor Milk Banking}

While HMBANA oversees some forms of milk banking in the United States, the organization is not an adequate substitute for fed- eral regulation. First, silence from the federal government only exasperates the informal circulation of breast milk and the ease with which misinformation is spread.(1) For example, stories about parents purchasing contaminated breast milk online have unfortunately become an increasingly popular headline in U.S. news.(88, 89) These articles can indirectly mislead the public about other, safer forms of breast milk sharing. Next, access to scrupulously tested breast milk is far more difficult in the U.S. than in countries with strong government-support for milk banks and robust regulatory systems. Specifically, even though breast milk is theoretically abundant, many infants cannot obtain this ideal source of nutrients in the United States. This unfortunate reality exists because safe breast milk is either difficult to obtain, expensive, or because parents and policymakers are misinformed about safe milk sharing practices.(53). Increased regulation and oversight over breast milk banking would undoubtedly address many of these concerns.(1) Specially, federal support of breast milk banking would increase the number of institutionalized breast milk banks in each state, and would also remove some of the economic burdens to accessing breastmilk.(53) Most notably, federal regulation would additionally discourage the informal market in breast milk sharing. (1)

"Specially, federal support of breast milk banking would increase the number of institutionalized breast milk banks in each state, and would also remove some of the economic burdens to accessing breastmilk.(53) Most notably, federal regulation would additionally discourage the informal market in breast milk sharing."

Unfortunately, the prevalence of issues that could be resolved with more regulation on breast milk banking is not a situation that is unique to the United States. There are many nations that do not have any substantive regulation on donating and sharing breast milk. In sum, these countries exemplify the urgent need for the WHO to move forward with evidence-based standards and procedures on breast milk sharing, so that more countries are inclined to regulate this practice.(13)

\section{WHO's Integral Role on Global Health Promotion}

WHO is the principal leader in global health. The Organization is comprised of 194 Member States (90) and therefore, has access to the "best international experts" on matters of science, medicine, ethics, and human rights.(91) Each year, all WHO Member States gather together in Geneva, Switzerland, to facilitate global governance regarding matters of health and disease.(92) The purpose of WHO is to "promote health, keep the world safe, and serve the vulnerable."(93) Appropriately, WHO has played a vital role in the eradication of small pox, improving the treatment of tuberculosis, and executing vaccinations against common infections in many countries. (91) WHO has and will continue to have a significant impact on world health because of its rare and extensive "legal" and "normative" authority.(94)

\section{WHO's Legal Authority}

First, WHO has the legal authority to make binding law. More 
specifically, Articles 2, 19, and 21 of WHO Constitution grant the Organization the power to make binding international law through conventions, agreements, and regulations. (95) WHO's law-making powers are exceptionally important because it is unusual in international law for a governing body to impose affirmative requirements on sovereign states. (94) For instance, by exercising the Organization's Article 21 powers, the World Health Assembly adopted the International Health Regulations (hereinafter "IHR"), which imposed requirements on all Member States. (96) The IHR (2005) mandated that all countries have the ability to do the following:

1) Detect: Make sure surveillance systems and laboratories can detect potential threat

2) Assess: Work together with other countries to make decisions in public health emergencies

3) Report: Report specific diseases, plus any potential international public health emergencies, through participation in a network of National Focal Points

\section{4) Respond: Respond to public health events (97)}

The IHR (2005) was created to keep the world informed about certain infectious disease outbreaks by ensuring that each country "develop, strengthen, and maintain core public health capacities." (98) Notably, both government leaders and non-governmental health agencies admit that their own accomplishments in disease prevention and control are "largely rooted [in] WHO's constitutionally mandated policies and programs." (96) While WHO is avidly employing reforms to better respond to global health threats,(94) The IHR represents a step in the right direction for coordinating global health activities.(96) Ultimately, WHO's ability to create and implement instruments of international law can be an effective tool for generating consensus and change.(94)

\section{WHO's Normative Authority}

In addition, WHO has the normative authority to make highly influential proposals can coordinate several State actors toward a common goal.(94) Specifically, Article 23 grants the Assembly the authority to make recommendations to Member States. Furthermore, Article 62 requires States to report the actions they have taken to comply with WHO's recommendations.(95) Even without a compulsory obligation, many countries comply with the norms and standards set forth by WHO because of its "high social capital and credibility."(91) Furthermore, the Organizations recommendations often become the building blocks of national legislation. By way of example, one of WHO's "most prominent" recommendations have been the International Code of Marketing of Breast Milk Substitutes (1981).(94) Several countries incorporated the International Code into their legislation. What is more, countries that adopted legislation reflecting the provisions of the International Code demonstrated an increase in breastfeeding rates. (99) WHO's recommendation, in effect, furthered its objective to increase the proportion of infants who are ever breastfed. (100) It is evident that WHO's normative authority can have an immense impact on global health.(94)

\section{Analysis and Recommendation}

It is unclear why WHO has failed to exercise its normative and legal authority to address the large regulatory gap that exists in breast milk. Perhaps WHO has not endorsed any standards on breast milk sharing because this practice has always existed, so a guiding framework may not seem necessary. Yet, if WHO were to provide global guidelines on safe and effective milk banking, more countries would be inclined to regulate this practice. This, in effect, would help safeguard the health and well-being of the world's most defenseless population. It is therefore imperative that $\mathrm{WHO}$ endorses a set best practices regarding the selection and examination of breast milk.(94)

WHO's best practices for breast milk donation and sharing should first begin by recommending that institutionalized milk banks are complying with scientific standards and discouraging the informal circulation of breast milk.(1) Thereafter, WHO's best practices should include guidelines for screening potential donors. (3) More specifically, WHO should require donors to be individuals who produce milk in excess of what their own children need. Notably, these recommendations largely resemble what Brazilian law requires. (49) It should further dictate that donors must be healthy individuals who are not taking any drugs, alcohol, or unsafe medications at the time at the time of donation. The best practices should then recommend continuous and rigorous testing of donors, as well as a system for tracing and tracking the breast milk. Additionally, WHO should include guidelines for collecting, processing, handling, testing, and storing breast milk based on standards that have been endorsed by the scientific and medical community. These guidelines should contain the steps for handling both raw breast milk and pasteurized breast milk. WHO can subsequently discuss the pros and cons for pasteurizing breast milk against the pros and cons of using raw breast milk, and encourage individual lawmakers to decide which method would be a best fit for their community based on a nation's culture, resources, and disease risk pool.(3) Lastly, to help policymakers, researchers, and practitioners be as safe and successful as possible, this Note suggests that WHO should include a step-by-step map of the milk banking process that identifies points of potential hazards.

\section{Conclusion}

The practice of donating and sharing breastmilk has and will continue to escalate on a global scale. (13) Accordingly, WHO needs to address the regulatory gap in breast milk sharing by endorsing and promoting safe milk banking practices. A guiding framework on breast milk banking would also go hand in hand with many of WHO's own initiatives to improve infant health, such as the International Code of Marketing of Breast-milk Substitutes and the Global Strategy on Infant and Young Child Feeding. (99) Furthermore, since WHO explicitly recommends donated breast milk, it is only fitting that the organization provides some parameters for handling and sharing breast milk. Finally, if WHO can provide global guidelines on how cells, tissue, blood, and semen are handled and shared, then it is both possible and necessary for WHO to provide a similar framework for breast milk.(13)

\section{References}

1. Oparaeke C. White Milk, Black Market: A call for the Regulation of Human Breast Milk Over the Internet. Howard Law Journal. 2017;60:570-73.

2. Haiden $N$, Ziegler EE. Human Milk Banking. Ann Nutr Metab. 2016;69 Suppl 2:8-15. Epub 2017/01/20. doi: 10.1159/000452821. PubMed PMID: 28103607.

3. Health PfATi. Strengthening Human Milk Banking a Global Implementation Forward 2013. Available from: https://path. azureedge.net/media/documents/MCHN strengthen hmb frame Jan2016.pdf.

4. Miracle DJ, Szucs KA, Torke AM, Helft PR. Contemporary ethical issues in human milk-banking in the United States. Pediatrics. 2011;128(6):1186-91. Epub 2011/11/16. doi: 10.1542/peds.2010-2040. PubMed PMID: 22084324.

5. Petherick A. Milk Banks Around the World International Milk Genomics Consortium2015. Available from: https://milkgenomics.org/article/milk-banks-around-the-world/.

6. Baumgartel KL, Sneeringer L, Cohen SM. From royal wet nurses to Facebook: The evolution of breastmilk sharing. Breastfeed Rev. 2016;24(3):25-32. Epub 2017/09/25. 
PubMed PMID: 28936030; PubMed Central PMCID: PMCPMC5603296.

7. Geraghty SR, Heier JE, Rasmussen KM. Got milk? Sharing human milk via the Internet. Public Health Rep. 2011;126(2):161-4. Epub 2011/03/11. doi: 10.1177/003335491112600204. PubMed PMID: 21387943; PubMed Central PMCID: PMCPMC3056026.

8. Kenna J. Got Milk? A Call for Federal Regulation and Support of Human Donor Milk 2015. Available from: https:// heinonline.org/HOL/LandingPage? handle=hein.journals/ worts36\&div $=23 \& i d=$ \&page $=$.

9. GB LLL. Sharing Breast Milk. Available from: https://www. laleche.org.uk/sharing-breastmilk/.

10. Sriraman NK, Evans AE, Lawrence R, Noble L, Academy of Breastfeeding Medicine's Board of D. Academy of Breastfeeding Medicine's 2017 Position Statement on Informal Breast Milk Sharing for the Term Healthy Infant. Breastfeed Med. 2018;13(1):2-4. Epub 2018/04/11. doi: 10.1089/ bfm.2017.29064.nks. PubMed PMID: 29634294.

11. Nangia S, Sachdeva, R., Sabharwal, V. . Human Milk Banking: An Indian Experience. NeoReviews. 2018;19(4). doi: https://doi.org/10.1542/neo.19-4-e201.

12. Committee On N, Section On B, Committee On F, Newborn. Donor Human Milk for the High-Risk Infant: Preparation, Safety, and Usage Options in the United States. Pediatrics. 2017;139(1). Epub 2016/12/21. doi: 10.1542/peds.20163440. PubMed PMID: 27994111.

13. Green A. The Gap in Global Guidelines in Human Milk Banking. 2018.

14. Organization WH. WHO laboratory manual for the examination and processing of human semen 2010. Available from: https://www.who.int/publications/i/item/9789241547789.

15. Organization WH. World Health Organization's Infant Feeding Recommendation.

16. Organization WH. Global Targets 2025.

17. Arnold C. The Rise and Fall and Rise of Breast Milk Banking Mosaic Science2015. Available from: https://mosaicscience. com/story/rise-and-fall-and-rise-breast-milk-banking/.

18. Kimani-Murage EW, Wanjohi MN, Kamande EW, Macharia TN, Mwaniki E, Zerfu T, et al. Perceptions on donated human milk and human milk banking in Nairobi, Kenya. Matern Child Nutr. 2019;15(4):e12842. Epub 2019/05/18. doi: 10.1111/mcn.12842. PubMed PMID: 31099159; PubMed Central PMCID: PMCPMC6859964.

19. Kim J, Unger S. Human milk banking. Paediatr Child Health. 2010;15(9):595-602. Epub 2011/11/02. PubMed PMID: 22043143; PubMed Central PMCID: PMCPMC3009567.

20. Bilich K. All About Formula Explore Parents2005. Available from: $\quad$ https://www.parents.com/baby/feeding/formula/allabout-formulal.

21. Weaver G, Bertino E, Gebauer C, Grovslien A, MileusnicMilenovic $R$, Arslanoglu $S$, et al. Recommendations for the Establishment and Operation of Human Milk Banks in Europe: A Consensus Statement From the European Milk Bank Association (EMBA). Front Pediatr. 2019;7:53. Epub 2019/03/20. doi: 10.3389/fped.2019.00053. PubMed PMID: 30886837; PubMed Central PMCID: PMCPMC6409313.

22. Arnold LD. Global health policies that support the use of banked donor human milk: a human rights issue. Int Breastfeed J. 2006;1:26. Epub 2006/12/14. doi: 10.1186/17464358-1-26. PubMed PMID: 17164001; PubMed Central PMCID: PMCPMC1766344.

23. Hauck FR, Thompson JM, Tanabe KO, Moon RY, Vennemann MM. Breastfeeding and reduced risk of sudden infant death syndrome: a meta-analysis. Pediatrics. 2011;128(1):103-10. Epub 2011/06/15. doi: 10.1542/peds.2010-3000. PubMed PMID: 21669892.

24. Armstrong J, Reilly JJ, Child Health Information T. Breast- feeding and lowering the risk of childhood obesity. Lancet. 2002;359(9322):2003-4. Epub 2002/06/22. doi: 10.1016/ S0140-6736(02)08837-2. PubMed PMID: 12076560.

25. Wennberg AL, Jonsson S, Zadik Janke J, Hornsten A. Online Perceptions of Mothers About Breastfeeding and Introducing Formula: Qualitative Study. JMIR Public Health Surveill. 2017;3(4):e88. Epub 2017/11/17. doi: 10.2196/publichealth.8197. PubMed PMID: 29141838; PubMed Central PMCID: PMCPMC5707429.

26. Murray D. Why Some People Shouldn't or Can't Breastfeed VeryWellFamily2011. Available from: https://www.verywellfamily.com/why-some-women-cant-breastfeed-4153606.

27. USDA. Breastfeeding and Alcohol, Drugs and Smoking WIC Breastfeeding Support. Available from: https://wicbreastfeeding.fns.usda.gov/breastfeeding-and-alcohol-drugs-andsmoking.

28. Ogbuanu CA, Probst J, Laditka SB, Liu J, Baek J, Glover S. Reasons why women do not initiate breastfeeding: A southeastern state study. Womens Health Issues. 2009;19(4):26878. Epub 2009/07/11. doi: 10.1016/j.whi.2009.03.005. PubMed PMID: 19589476; PubMed Central PMCID: PMCPMC2865685.

29. Organization WH. Born Too Sooon: The Global ACtion Report on Preterm Birth 2012. Available from: https://www. who. int/pmnch/media/news/2012/201204 borntoosoon-report. pdf.

30. Sachdeva R. Breast Milk is a Superfood for Babies. So Why Do So Many Babiesz Go Without? PATH2018. Available from: https://www.path.org/articles/breast-milk-superfoodall-babies-need/.

31. Ortiz-Ospina E, Tzvetkova, S. . Working Women: Key Facts and Trends in Female Labor Force Participation. Our World in Data. 2017.

32. Organization WH. Breastfeeding Policy: A Globally Comparative Analysis 2013. Available from: https://www.who.int/ bulletin/volumes/91/6/12-109363/en/.

33. Fentiman LC. Marketing Mothers' Milk: The Commodification of Breastfeeding and the New Markets for Breast Milk and Infant Formula 2019.

34. Freile V. New Working Mom: Donating Breast Milk Democrat and Chronicle 2017. Available from: https://www. democratandchronicle.com/story/news/2017/02/10/newworking-mom-donating-breast-milk/97285574/.

35. Cohen M. Regulating Milk: Women and Cows in France and the United States. American Journal of Comparative Law. 2017;65:469-526.

36. GB LLL. Breastfeeding and the Environment. Available from: $\quad$ https://www.laleche.org.uk/breastmilk-and-the-environment/.

37. Lawrence RM, Lawrence RA. Breast milk and infection. Clin Perinatol. 2004;31(3):501-28. Epub 2004/08/25. doi: 10.1016/j.clp.2004.03.019. PubMed PMID: 15325535; PubMed Central PMCID: PMCPMC7133241.

38. David SD. Legal commentary on the Internet sale of human milk. Public Health Rep. 2011;126(2):165-6. Epub 2011/03/11. doi: 10.1177/003335491112600205. PubMed PMID: 21387944; PubMed Central PMCID: PMCPMC3056027.

39. McNeilly C. Got Milk: The Underground Online Marketplace for Human Breast Milk Vice2016. Available from: https:// www. vice.com/en/article/pg7ndn/got-milk-the-undergroundonline-marketplace-for-human-breast-milk.

40. SGS. Global Regulatory Requirements for Baby Food 2015. Available from: https://www.sgs.com/en/news/2015/12/global-regulatory-requirements-for-baby-food.

41. Apolitcal. South Africa's Milk Banks have Saved Thousands of Babies'Lives 2017. Available from: https://apolitical.co/en/ solution article/south-africas-milk-banks-saved-thousands- 
babies-lives.

42. DeMarchis A, Israel-Ballard K, Mansen KA, Engmann C. Establishing an integrated human milk banking approach to strengthen newborn care. J Perinatol. 2017;37(5):469-74. Epub 2016/11/11. doi: 10.1038/jp.2016.198. PubMed PMID: 27831549; PubMed Central PMCID: PMCPMC5415705.

43. Ortiz F. Breast Milk Banks, From Brazil to the World Inter Press Service News Agency. 2012.

44. Pittas TM, Dri CF. The dialog between health and foreign policy in Brazilian cooperation in human milk banks. Cien Saude Colet. 2017;22(7):2277-86. Epub 2017/07/21. doi: 10.1590/1413-81232017227.02832017. PubMed PMID: 28724009.

45. Gutierrez D, de Almeida JA. Human milk banks in Brazil. J Hum Lact. 1998;14(4):333-5. Epub 1999/04/17. doi: 10.1177/089033449801400426. PubMed PMID: 10205454.

46. Picaud JC. Milk Banking Worldwide World Neonatology2017. Available from: https://worldneonatology.com/2019/ wp-content/uploads/2016/10/Human-Milk-Banking ProfJean-Charles-Picaud-1.pdf.

47. Fiocruz. Science at the service of life Oswaldo Cruz Foundation. Available from: https://portal.fiocruz.br/en/scienceservice-life.

48. Izquierdo S. Brazil's Maternal Milk Banks A Global Model. NBC News. 2014.

49. RDC-ANVISA No. 171 4.13, Diário Oficial da União [D.O.U.], Sept. 4, 2006, (Braz.) (translated by author)

50. RDC-ANVISA No. 171 6.2.2 Diário Oficial da União [D.O.U.], September 4, 2006, (Braz.) (translated by author)

51. RDC-ANVISA No. 171 6.2.4 Diário Oficial da União [D.O.U.], September 4, 2006, (Braz.) (translated by author).

52. Fernandes MS, Silla L, Goldim JR, Martins-Costa J. Brazilian legal and bioethical approach about donation for research and patents of human body parts. J Community Genet. 2017;8(3):199-208. Epub 2017/05/31. doi: 10.1007/ s12687-017-0303-y. PubMed PMID: 28555435; PubMed Central PMCID: PMCPMC5496841.

53. Cohen M. Should Human Milk Be Regulated? UC Irvine Law Review. 2019.

54. Schreiber M. Should Women Be Paid for Donating Their Breast Milk? Atlantic 2017. Available from: https://www. theatlantic.com/health/archive/2017/12/breast-milk-donation/547250/

55. RDC-ANVISA No. 171 6.4.1, 6.5, 6.5.1-4 DIÁRIO OFICIAL DA UNIÃO [D.O.U.], de 9.4.2006, (Braz.) (translated by author).

56. RDC-ANVISA No. 171 6.3.3 DIÁRIO OFICIAL DA UNIÃO [D.O.U.], de 9.4.2006, (Braz.) (translated by author)

57. RDC-ANVISA No. 171 6.8.2.1 DIÁRIO OFICIAL DA UNIÃO [D.O.U.], de 9.4.2006, (Braz.) (translated by author).

58. Garcia-Lara NR, Vieco DE, De la Cruz-Bertolo J, LoraPablos D, Velasco NU, Pallas-Alonso CR. Effect of Holder pasteurization and frozen storage on macronutrients and energy content of breast milk. J Pediatr Gastroenterol Nutr. 2013:57(3):377-82. Epub 2013/06/12. doi: 10.1097/ MPG.0b013e31829d4f82. PubMed PMID: 23752081.

59. O’Connor DL, Ewaschuk JB, Unger S. Human milk pasteurization: benefits and risks. Curr Opin Clin Nutr Metab Care. 2015;18(3):269-75. Epub 2015/03/15. doi: 10.1097/ MCO.0000000000000160. PubMed PMID: 25769062.

60. Barchfield J. Brazil's Extensive Network of Maternal Breast Milk Banks a Model for Globe. Fox Business. 2015.

61. Rea MF. The Brazilian National Breastfeeding Program: a success story. Int J Gynaecol Obstet. 1990;31 Suppl 1:7982; discussion 3-4. Epub 1990/01/01. doi: 10.1016/00207292(90)90082-V. PubMed PMID: 1972092.

62. Boccolini CS, Boccolini PMM, Monteiro FR, Venancio SI, Giugliani ERJ. Breastfeeding indicators trends in Brazil for three decades. Rev Saude Publica. 2017:51:108. Epub 2017/11/23. doi: 10.11606/S1518-8787.2017051000029. PubMed PMID: 29166437; PubMed Central PMCID: PMCPMC5697916.

63. Passanha A, Benicio MH, Venancio SI, Reis MC. [Implementation of the Brazilian Breastfeeding Network and prevalence of exclusive breastfeeding]. Rev Saude Publica. 2013;47(6):1141-7; discussion 8. Epub 2014/03/15. doi: 10.1590/s0034-8910.2013047004807. PubMed PMID. 24626552; PubMed Central PMCID: PMCPMC4206096.

64. Santos IS, Barros FC, Horta BL, Menezes AMB, Bassani $D$, Tovo-Rodrigues $L$, et al. Breastfeeding exclusivity and duration: trends and inequalities in four population-based birth cohorts in Pelotas, Brazil, 1982-2015. Int J Epidemiol. 2019;48(Suppl 1):i72-i9. Epub 2019/03/19. doi: 10.1093/ije/ dyy159. PubMed PMID: 30883659; PubMed Central PMCID: PMCPMC6422059.

65. Arnold LD. Human Milk in the NICU: Policy into Practice2010.

66. Perrin M. "World Day of Human Milk Donation" - An International Effort Lactional Matters2013. Available from: https:// lactationmatters.org/2013/04/23/world-day-of-human-milkdonation-an-international-effort/.

67. Creación del "Día Mundial de Donación de Leche Humana, 2010. Available from: http://www.iberb/h.icict.fiocruz.br/index.php?option $=$ com content\&view=article\&id $=106 \& /$ tem id=94.

68. World Human Milk Donation Day: 6 Ways for Americans to Celebrate Marie Biancuzzo2019. Available from: https:// mariebiancuzzo.com/2019/05/21/world-human-milk-donation-day-6-ways-for-americans-to-celebratel.

69. World Day of Human Milk Donation European Milk Banking Available from: https://europeanmilkbanking.com/world-dayof-human-milk-donation/.

70. World Day of Human Milk Donation Mothers'Milk Bank Northeast2016. Available from: https://milkbankne.org/2016/05/ world-day-of-human-milk-donation/.

71. Pires F. Learning from Brazil's Success with Milk Banks Michigan News2014. Available from: https://news.umich. edu/learning-from-brazil-s-success-with-milk-banks/.

72. Health AGDo. Norway - The WHO Code and Breastfeeding: An International Comparative Overview, 2012.

73. Norway Population World Meter2020. Available from: https:// www.worldometers.info/world-population/norway-population/.

74. Brazil Population World Meter2020. Available from: https:// www.worldometers.info/world-population/brazil-population/.

75. Grovslien $A H$, Gronn M. Donor milk banking and breastfeeding in Norway. J Hum Lact. 2009;25(2):206-10. Epub 2009/05/06. doi: 10.1177/0890334409333425. PubMed PMID: 19414822.

76. Norway European Milk Banking. Available from: https://europeanmilkbanking.com/country/norway/.

77. NORSK BARNELEGEFORENING [NORWEGIAN PEDIATRIC ASSOCIATION] (translated by author). Drift av Morsmelkbanker [Operation of Breast Milk Banks]

78. Health AGDo. An International Comparison Study into the Implementation of the WHO Code and other Breastfeeding Initiatives 2020. Available from: https://www1.health.gov.aul internet/main/publishing.nsf/Content/int-comp-whocode-bfinit.

79. About EMBA European Milk Bank Association Available from: https:/leuropeanmilkbanking.com/about-embal.

80. Mumbai RnEiNDaCGi. Breastfeeding: Foundation of Life. Available from: https://www.norway.no/en/indial.

81. Raestad EW. Promotion, Protection and Support of Breastfeeding in Norway: Charles University; 2010.

82. UNICEF. Norway. Available from: https://data.unicef.org/ country/norl. 
83. America HMBAoN. Mission and Vision 2021. Available from: https://www.hmbana.org/about-us/mission.html.

84. Administration USFD. Use of Donor Human Milk 2018. Available from: https://www.fda.gov/science-research/pediatrics/ use-donor-human-milk.

85. America HMBAoN. Find a Milk Bank 2021. Available from: https://www.hmbana.org/find-a-milk-bank/overview.html.

86. America HMBAoN. About 2021. Available from: https://www. hmbana.org/about-us/overview.html.

87. Ruhe N. The Battle Over Breast Milk: For-Profit Milk Banks Versus Non-Proft Milk Banks. MedCity News. 2015.

88. Aleccia J. Much Breast Milk Bought Online is Contaminated, Analysis Shows. NBC News. 2013.

89. Preston E. With the Rise of Informal Breastmilk Sharing, Questions of Safety Linger Undark2018. Available from: https://undark.org/2018/03/12/breastmilk-sharing-networksonline-safetyl.

90. Organization WH. About: Better Health for Everyone, Everywhere. Available from: https://www.who.int/about/what-wedo/who-brochure.

91. Wibulpolprasert S, Chowdhury M. World Health Organization: Overhaul or Dismantle? Am J Public Health. 2016;106(11):1910-1. Epub 2016/10/08. doi: 10.2105/ AJPH.2016.303469. PubMed PMID: 27715308; PubMed Central PMCID: PMCPMC5055803.

92. Organization WH. World Health Assembly. Available from: https://www.who.int/about/governance/world-health-assembly.

93. Organization WH. About: What We Do. Available from: https://www. who.int/about/what-we-do.

94. Gostin LO, Sridhar D, Hougendobler D. The normative authority of the World Health Organization. Public Health. 2015;129(7):854-63. Epub 2015/06/24. doi: 10.1016/j. puhe.2015.05.002. PubMed PMID: 26100341.

95. Organization WH. Constitution of the World Health Organization 1946. Available from: https://www.who.int/governance/eb/who constitution en.pdf.

96. Volansky M. Achieving Global Health: A Review of the World Health Organization's Response. Tulsa Journal of Comparative and International Law. 2002;10(1).

97. CDC. International Health Regulation. Available from: $\underline{h t t p s: / /}$ www.cdc.gov/globalhealth/healthprotection/ghs/ihr/index. $\underline{\text { html. }}$.

98. Organization WH. Frequently Asked Questions about the International Health Regulations 2005. Available from: https:// www.who.int/ihr/about/fag/en/.

99. Soldavini J, Taillie LS. Recommendations for Adopting the International Code of Marketing of Breast-milk Substitutes Into U.S. Policy. J Hum Lact. 2017;33(3):5827. Epub 2017/04/19. doi: 10.1177/0890334417703063. PubMed PMID: 28418755; PubMed Central PMCID: PMCPMC5515674.

100. Organization WH. Promoting Proper Feeding for Infants and Young Children. Available from: https://www.who.int/nutrition/topics/infantfeeding/en/.

Disclosure: The author has no relevant disclosures

NT

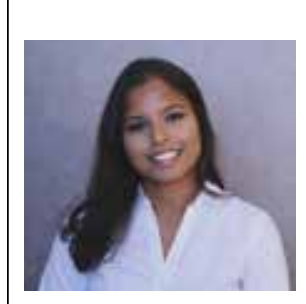

Corresponding Author

Jasmine Shafquat JD

Law Clerk

Dillon \& Samuel, PLLC

Email:jasmine@dillonandsamuel.com

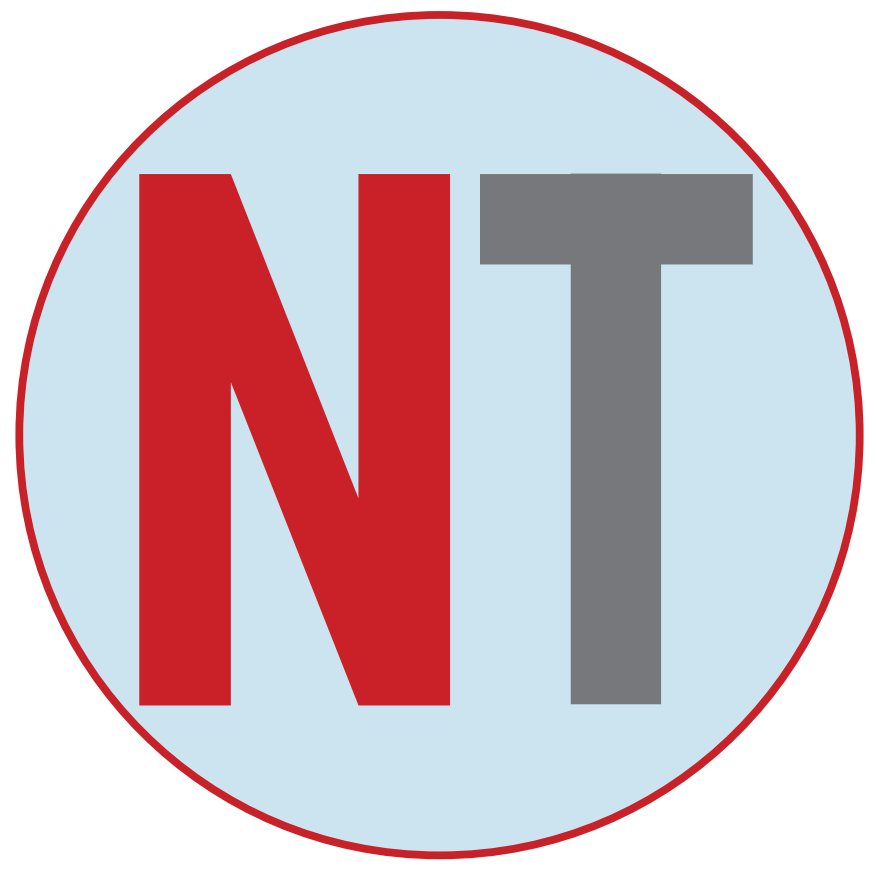

Readers can also follow NEONATOLOGY TODAY

via our Twitter Feed @NEOTODAY 